\title{
Flipped Classroom-Computer Based Instruction untuk Pembelajaran Revolusi Industri 4.0: Rancang Bangun dan Analisis Kebutuhan
}

\author{
Rizki Hardian Sakti ${ }^{1 *}$, Sukardi ${ }^{2}$, Muhammad Giatman ${ }^{3}$, Ernawati Nazar $^{4}$, \\ Wakhinuddin ${ }^{5}$, Waskito ${ }^{6}$ \\ 1,2,3,4,5,6 Program Studi Pendidikan Teknologi dan Kejuruan, Universitas Negeri Padang \\ email: rizki.hardian29@gmail.com ${ }^{1}$, sukardiunp@gmail.com², giatman@ft.unp.ac.id ${ }^{3}$, \\ ernawatiunp44@gmail.com ${ }^{4}$,wakhid_nuddin@yahoo.com ${ }^{5}$, waskito@ft.unp.ac.id ${ }^{6}$
}

(Received: 29 April 2020/ Accepted: 29 Mei 2020 / Published Online: 20 Juni 2020)

\begin{abstract}
Abstrak
Teknologi telah mencapai tingkat di mana saat ini adalah saat untuk reformasi pendidikan yang meningkatkan pencapaian konten siswa dengan mengajarkan pembelajaran yang relevan dengan revolusi industri 4.0. Pada era revolusi industri 4.0 ini, salah satu tantangan yang dihadapi pendidikan ialah penggarapan teknologi baru. Karena siswa terbiasa dengan teknologi baru, pembelajaran dengan menggunakan lembar kerja dan mendengarkan presentasi tanpa media terkesan monoton dan membosankan. Hal itu menjadi dasar perlunya media yang menarik seperti Computer Based Instruction-Flipped Classroom (CBIFC). Tujuan dari penelitian ini adalah untuk menentukan analisis kebutuhan dan desain dari CBIFC. Metode yang digunakan pada penelitian ini adalah SDLC (System Development Life Cycle) waterfall. Untuk analisis kebutuhan instrumen yang digunakan menggunakan kuisioner analisis kebutuhan. Hasil dari analisis kebutuhan didapatkan bahwa usia siswa SMK berada pada rentang 15 tahun sampai 18 tahun, dimana siswa SMK tengah memasuki tahapan perkembangan masa remaja. Karakteristik siswa pada usia tersebut memiliki kecenderungan menyukai warna-warna kontras, tetapi tidak mencolok. Untuk memadukan komponen warna, musik, dan kreativitas siswa dalam belajar dengan menyenangkan, maka dari itu sebelum mengembangkan CBIFC, dilakukan desain menggunakan flowchart, Unified Modeling Language (UML), yang terdiri dari desain use case dan sequence diagram.
\end{abstract}

Kata kunci: Analisis Kebutuhan, Computer Based Instruction-Flipped Classroom, Desain, Komputer dan jaringan Dasar

\begin{abstract}
Technology has influenced educational reforms, thus improving students' content knowledge by providing learning relevance. In this era, the challenges faced by education include the creation of new technology, and students need an interesting media such as Computer-Based Instruction-Flipped Classroom (CBIFC). Therefore, this study aimed to determine need's analysis and design of the CBIFC. The method used was the SDLC (System Development Life Cycle) waterfall and instrument for needs analysis was a questionnaire. The results show that vocational students' age is between 15 of 18 where they get into the adolescent stage of development. Their characteristic at this age is the tendency to like contrasting colors, music, and creativity components of students in fun learning, before developing the CBIFC, which is done using a flowchart, and Unified Modelling Language (UML), that consists of a use case and sequence diagram design.
\end{abstract}

Keywords: Computer Based Instruction-Flipped Classroom, Computer networking, Design, Need analysis

\section{PENDAHULUAN}

Perkembangan Ilmu Pengetahuan dan Teknologi (IPTEK) telah membawa perubahan di hampir semua aspek kehidupan manusia. Perubahan tersebut juga membawa manusia ke 
dalam era persaingan global yang semakin hari semakin ketat (Ahmed \& Parsons, 2013; Hermann, Pentek, \& Otto, 2016; Hermann et al., 2016). Agar bisa berperan dalam persaingan global, maka kita sebagai bangsa negara perlu mengembangkan dan meningkatkan kualitas sumber daya manusia. Salah satu upaya untuk menghasilkan sumber daya manusia yang unggul dan berkualitas tersebut adalah melalui pendidikan (Ai, 2017).

Saat ini, siswa dibesarkan pada era teknologi media terbaru, jadi siswa akan kurang sabar dan bosan jika mereka hanya mengisi lembar kerja dan mendengarkan ceramah saja (Collins \& Halverson, 2009). Teknologi telah mencapai tingkat di mana saat ini adalah saat untuk reformasi pendidikan sejati yang meningkatkan pencapaian konten siswa dengan mengajarkan pembalajaran yang relevan dengan revolusi industri 4.0 (Jaschke, 2015). Pada era revolusi industri 4.0 ini, tantangan yang dihadapi pendidikan melibatkan penggarapan teknologi baru.

Media pendidikan sebagai salah satu sarana meningkatkan mutu pendidikan sangat penting dalam proses pembelajaran (Amaral \& Meurers, 2011). Media pembelajaran merupakan salah satu alat untuk mempermudah transfer ilmu dari guru kepada siswa (Sukardi, Puyada, Wulansari, \& Yanto, 2017). Penggunaan media pendidikan dapat mempertinggi proses belajar siswa dalam poses belajar mengajar yang pada gilirannya dapat mempertinggi hasil belajar yang dicapainya (Jia et al., 2013). Media pendidikan dapat berupa model/alat peraga, flowchart, tabel-tabel, dan media berbasis komputer (Wulansari, Puyada, Wijaya, \& Rukun, 2017; Sukardi et al., 2017; Rosen, 2009). Media pembelajaran dapat membantu siswa dalam memahami dan mengaplikasikan konsep pembelajaran, sehingga tujuan pembelajaran dapat dicapai oleh siswa (Wulansari et al., 2017).

Strategi dalam pendidikan formal yang lebih terbuka dan fleksibel adalah media pembelajaran berbasis computer (Perez, 2016). Komputer sebagai alat pendidikan dan pelatihan telah membantu membentuk lingkungan pendidikan. Media pembelajaran berbasis komputer dapat mengembangkan keterampilan siswa (Hawkins, 2016), sehingga media pembelajaran menggunakan komputer dalam proses pembelajaran sangatlah memegang peranan penting, seperti halnya multimedia pembelajaran interaktif (Sukardi et al., 2017), media animasi (Rosen, 2009), mobile learning (Crompton, Burke, Gregory, \& Gra, 2016), elearning yang memadukan flipped classroom (Rahayu, 2017), virtual lab (Kleintein \& Wannasawade, 2016) dan masih banyak lagi media pembelajaran berbasis komputer yang berkembang saat ini.

Flipped classroom adalah salah satu solusi media pembelajaran berbasis komputer yang relevan dengan perkembangan pembelajaran pada revolusi industri 4.0 (Overmyer, 2014; Kenna, 2014). Perkembangan teknologi Internet, komunikasi virtual, dan sistem manajemen pembelajaran, banyak instruktur perguruan tinggi dan universitas tertarik pada flipped classroom ini (Berrett, 2012; Bull, Ferster, \& Kjellstrom, 2012). Perkembangan penerapan flipped classroom dalam beberapa tahun terakhir menjelaskan bahwa flipped classroom telah efektif digunakan dalam pembelajaran (Bergmann \& Sams, 2012; Overmyer, 2014; Kenna, 2014). Model kelas terbalik telah secara anekdot terbukti meningkatkan pengaturan tujuan dan manajemen waktu (Bergmann \& Sams, 2012). Model pendidikan ini juga telah terbukti memenuhi kebutuhan berbagai gaya belajar (Marlowe, 2012). Penggunaan flipped classroom membuat pembelajaran langsung yang didaktik dan langsung menjauh dari ruang kelas menjadi lingkungan teknologi elektronik yang lebih ramah-siswa. Konsep pedagogis utama tidak berubah dengan penggunaan kelas terbalik tetapi sebaliknya mengubah mendengarkan dan belajar pasif untuk partisipasi aktif siswa di kelas (Nolan \& Washington, 2013). 
Kajian awal tentang desain Computer Based Instruction-Flipped Classroom merupakan hal yang penting dilakukan dalam pengembangan Computer Based Instruction-Flipped Classroom, karena guru membutuhkan sebuah paradigm bagaimana mereka dapat secara efektif mengintegrasikan Computer Based Instruction-Flipped Classroom di dalam kelas, untuk itu tujuan dari penelitian ini adalah untuk menentukan analisis kebutuhan dan desain dari Computer Based Instruction-Flipped Classroom.

\section{METODE}

Metode yang digunakan dalam penelitian ini adalah SDLC (System Development Life Cycle) Waterfall (Al Fatta, 2007). Metode ini memiliki pendekatan secara sisitematis mulai dari identifikasi, inisiasi dan perencanaan proyek, analisis, desain, implementasi, dan pemeliharaan, didalam pendekatan ini harus dilakukan secara berurut mulai dari tahap awal sampai akhir.

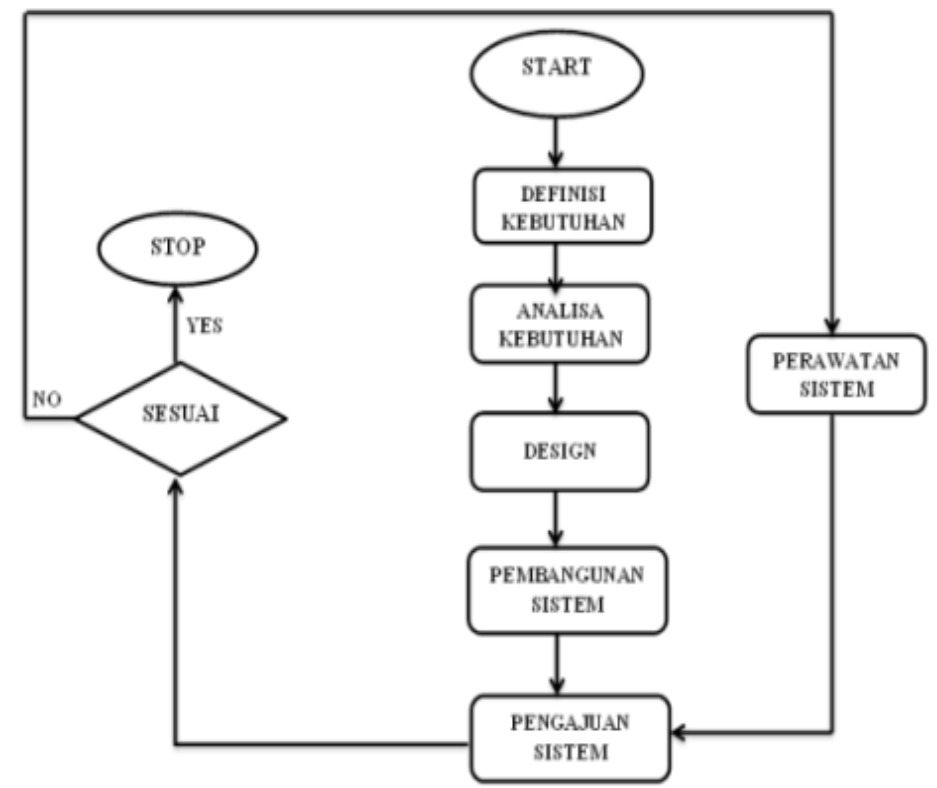

Gambar.1 Metode SDLC Waterfall

Sumber: Dimodifikasi dari Al Fatta, (2007

Analisis kebutuhan berada pada tahap satu, yaitu identifikasi. Sedangkan desain pada tahap ke empat. Pada tahap design sistem, peneliti menentukan konsep yang akan dirancang. Sedangkan pada langkah identifikasi ini merupakan tahap pengumpulan data dan penetapan kebutuhan semua elemen sistem. Tahapan analisis kebutuhan yang dilakukan adalah:

1. Analisis Siswa, dilakukan untuk mengetahui karakteristik siswa seperti latar belakang siswa, seperti kemampuan, perhatian, motivasi serta keterampilan yang sudah dimiliki siswa. Dengan diketahui karakteristik siswa, maka peneliti dapat merancang sebuah media pembelajaran yang sesuai dengan tingkat SMK.

2. Analisis Kurikulum dan materi, dilakukan untuk memastikan ulasan tentang seluruh materi pembelajaran yang akan disampaikan. Jadi, pada tahap ini peneliti harus menganalisis materi pembelajaran yang harus dikuasai oleh siswa untuk mencapai kompetensi minimal.

3. Analisis Capaian Pembelajaran, dilakukan peneliti menulis tujuan pembelajaran yang harus dicapai oleh siswa pada pembelajaran Komputer dan Jaringan Dasar. 


\section{HASIL DAN PEMBAHASAN}

\section{Hasil}

\section{Analisi Kebutuhan}

Computer Based Instruction-Flipped Classroom adalah salah satu solusi media terkini yang berbasis teknologi yang dapat digunakan oleh guru dalam proses pembelajaran baik daring maupun tidak (Bergmann \& Sams, 2012; Mclaughlin et al., 2014; Bernard, 2015). Computer Based Instruction-Flipped Classroom mempunyai karakteristik yang sesuai dengan era revolusi industri 4.0 saat ini, dimana Computer Based Instruction-Flipped Classroom ini berbasis teknologi yang melibatkan siswa secara aktif, sehingga Computer Based InstructionFlipped Classroom adalah salah satu solusi media pembelajaran berbasis komputer yang relevan dengan perkembangan pembelajaran pada revolusi industri 4.0 (Overmyer, 2014; Kenna, 2014).

Usia siswa SMK berada pada rentang 15 tahun sampai 18 tahun dimana siswa SMK tengah memasuki tahapan perkembangan masa remaja, dimana perkembangan kognitif siswa berada pada tahap pertumbuhan operasional formal (Trianto, 2012). Pada periode ini, idealnya siswa sudah memiliki pola pikir sendiri dalam usaha memecahkan masalah-masalah yang kompleks dan abstrak, serta siswa sudah dapat berpikir abstrak dan logis. Kemampuan berpikir abstrak setiap siswa tidak sama. Gambar dan animasi yang terdapat dalam media pembelajaran interaktif dapat membantu siswa dalam memahami konsep abstrak agar lebih mudah dipahami siswa. Karakteristik siswa pada usia tersebut memiliki kecenderungan menyukai warna-warna kontras, tetapi tidak mencolok, menyukai musik-musik dengan ritme dan harmoni bernuansa lembut, menyenangi karakter atau gambar-gambar animasi yang menarik. Memadukan komponen warna, musik, dan kreativitas siswa dapat menumbuhkan motivasi siswa dalam belajar. Komponen tersebut juga dapat meransang otak kanan siswa yang dapat membantu siswa dalam proses pembelajaran dan menyimpan pesan dalam waktu lama (Syah, 2005).

Berdasarkan analisis kurikulum dan analisis materi pada mata pelajaran Komputer dan Jaringan Dasar menjelaskan bahwa mata pelajaran Komputer dan Jaringan Dasar adalah mata pelajaran produktif yang pentik di banyak sekolah SMK pada jurusan Teknik Komputer dan Jaringan. Kurikulum pada mata pelajaran Komputer dan Jaringan Dasar ini berisikan materi tentang cara kerja internet, cara web berfungsi, cara mengatur jaringan operasional dan bagaimana memprogram jaringan untuk menyampaikan beragam aplikasi (Zaus \& Krismadinata, 2018; Purnama, Setiawan, \& Riasti, 2017). Analisis capaian pembelajaran mata pelajaran Komputer dan Jaringan Dasar ini menerangkan bahwa siswa harus menguasa konsep dasar jaringan komputer modern, siswa harus mampu mengembangkan aplikasi jaringan menggunakan bahasa pemrograman, siswa memahami arsitektur umum jaringan komputer dan bagaimana berlapis protokol jaringan komputer bekerja, siswa mampu mengidentifikasi dan menjelaskan topik saat ini di jaringan komputer, seperti keamanan dan kualitas layanan (Zaus \& Krismadinata, 2018).

\section{Desain rancangan}

Pada penelitian ini, peneliti mendesain Computer Based Instruction-Flipped Classroom ini dengan menggunakan flowchart dan Unified Modelling Language (UML).

\section{Flowchart}

Flowchart Diagram merupakan suatu bagan yang menggambarkan atau merepresentasikan algoritma atau prosedur untuk menyelesaikan masalah, berikut ini adalah flowchart dari Computer Based Instruction-Flipped Classroom. 


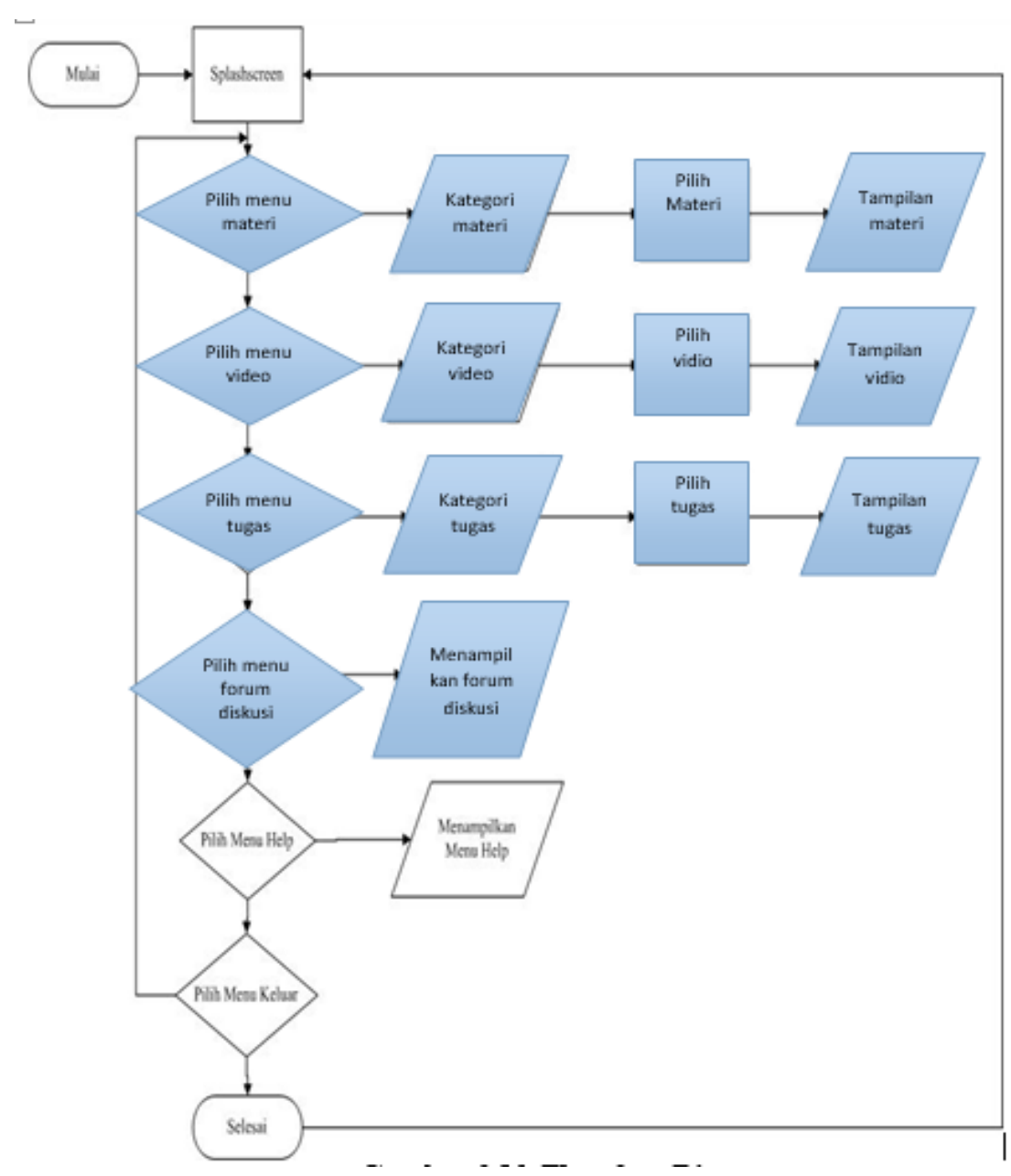

Gambar 2. Flowchart Computer Based Instruction-Flipped Classroom

Gambar 2 menjelaskan tentang flowchart dari pengembangan Computer Based Instruction-Flipped Classroom, dimana pada flowchat tersebut digambarkan bahwa pada pengembangan media Computer Based Instruction-Flipped Classroom terdapat menu materi, menu video, menu tugas dan forum diskusi. Flowchart tersebut menggambarkan tentang alur Computer Based Instruction-Flipped Classroom yang akan dikembangkan.

2. Use case diagram

Gambar 3 di bawah ini menjelaskan tentang keterurutan Computer Based InstructionFlipped Classroom oleh user. Keterurutan penggunaan Computer Based Instruction-Flipped Classroom mulai dari strat dan user harus mengisi form login untuk membuat akun untuk masing-masing user, dan user bisa mendapatkan ID dan password akun. Setelah itu, user bisa mengakses Computer Based Instruction-Flipped Classroom tersebut. Gambar 3 tersebut adalah Usecase Diagram Computer Based Instruction-Flipped Classroom yang menjelaskan tentang alur penggunaan Computer Based Instruction-Flipped Classroom, baik itu dari segi siswa, admin dan user bukan siswa, menjelaskan tentang runtutan tugas dari setiap pengguna pada Computer Based Instruction-Flipped Classroom. 

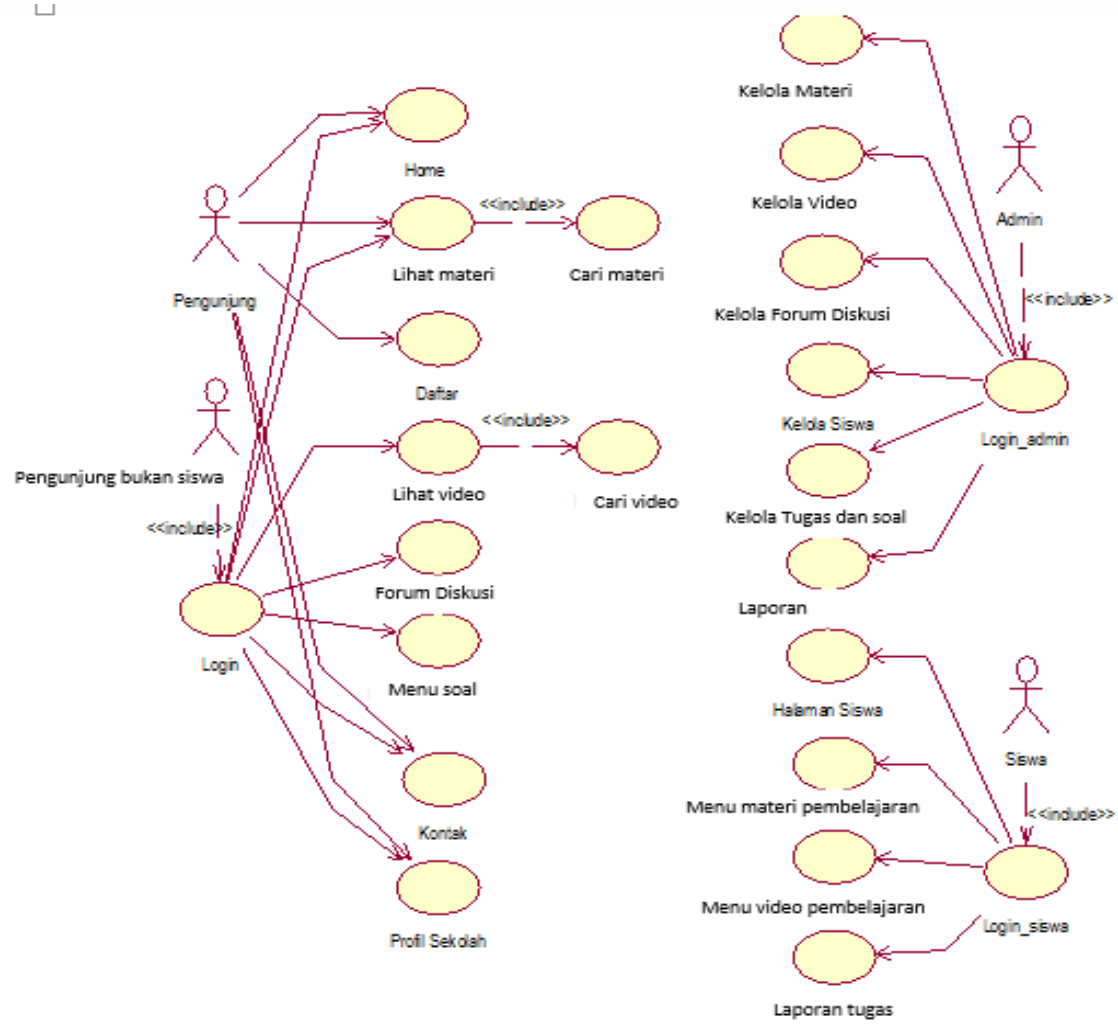

Gambar 3. Usecase Diagram Computer Based Instruction-Flipped Classroom

\section{Sequence diagram}

Sequence diagram biasa digunakan untuk menggambarkan skenario atau rangkaian langkah-langkah yang dilakukan sebagai respons dari sebuah event untuk menghasilkan output tertentu pada Computer Based Instruction-Flipped Classroom tersebut.

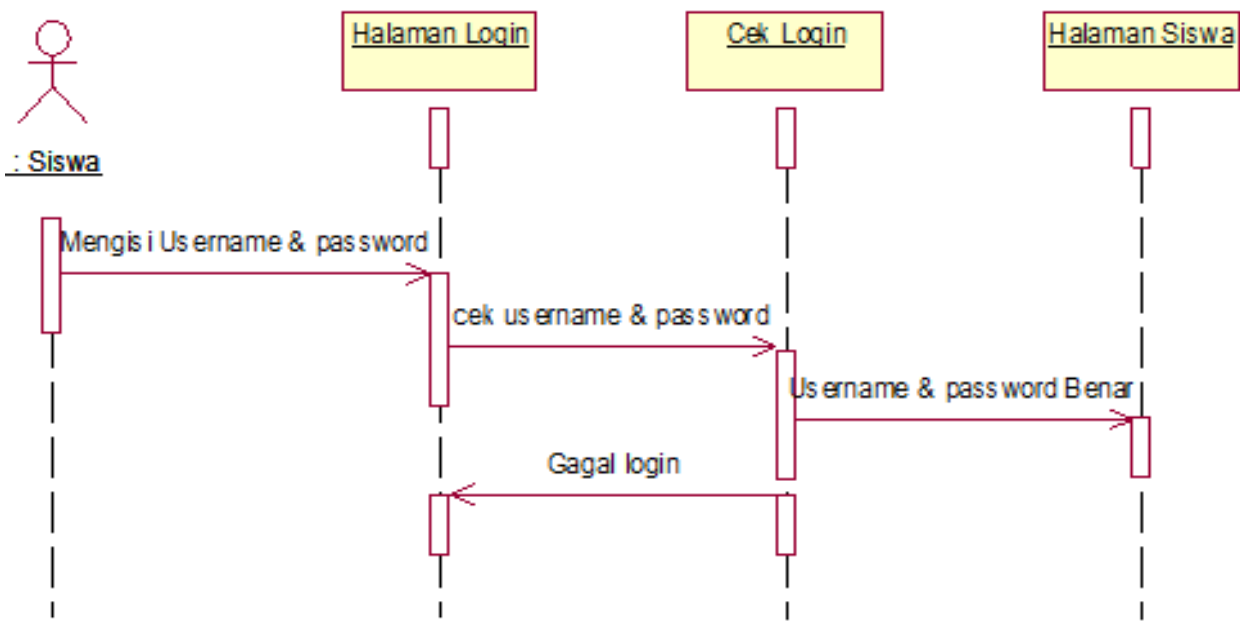

Gambar 4. Sequence Diagram Login Siswa

Gambar 4 adalah sequence diagram login siswa pada media Computer Based Instruction-Flipped Classroom, pada Gambar 4 ini menjelaskan tentang runtutan pekerjaan user yaitu siswa pada halaman login di Computer Based Instruction-Flipped Classroom. 


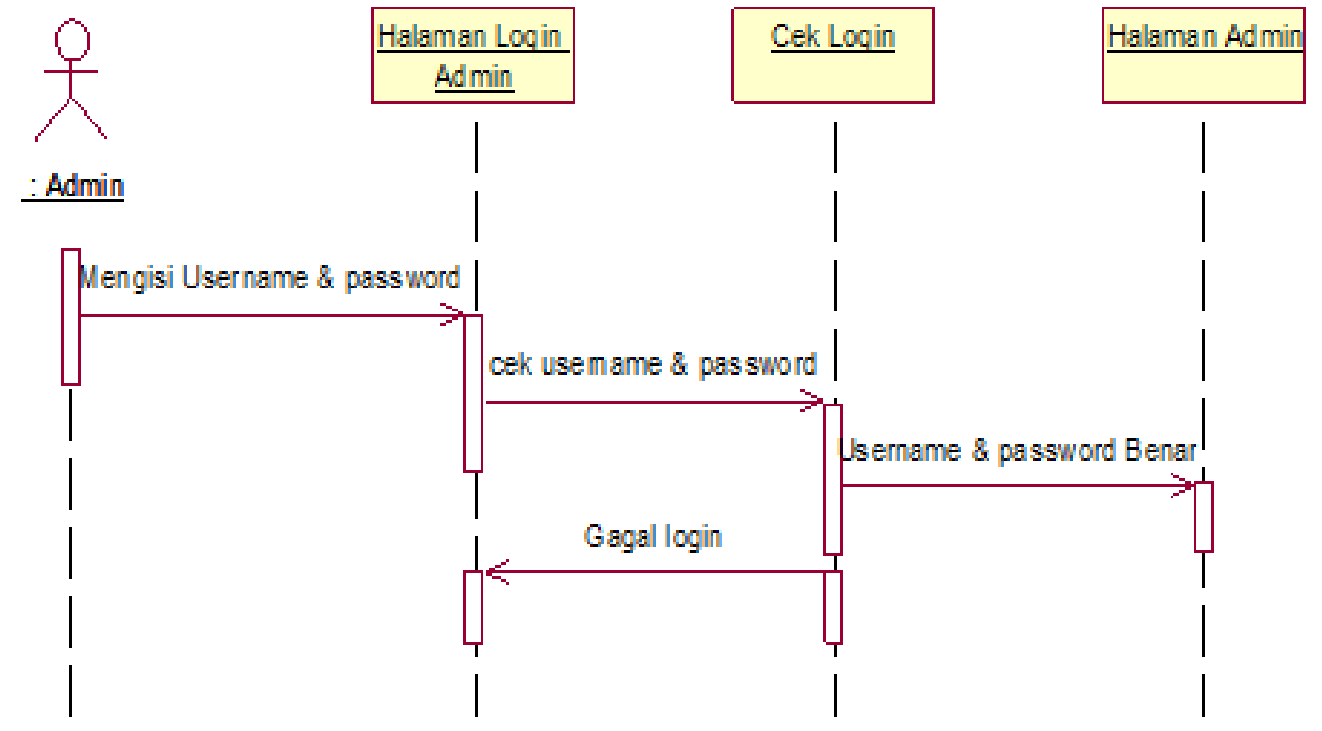

Gambar 5. Sequence Diagram Login Admin

Gambar 5 adalah sequence diagram login admin pada media Computer Based Instruction-Flipped Classroom, pada Gambar 5 ini menjelaskan tentang runtutan pekerjaan user yaitu admin, baik itu guru ataupun instruktur pembelajaran lainnya pada halaman login di Computer Based Instruction-Flipped Classroom.

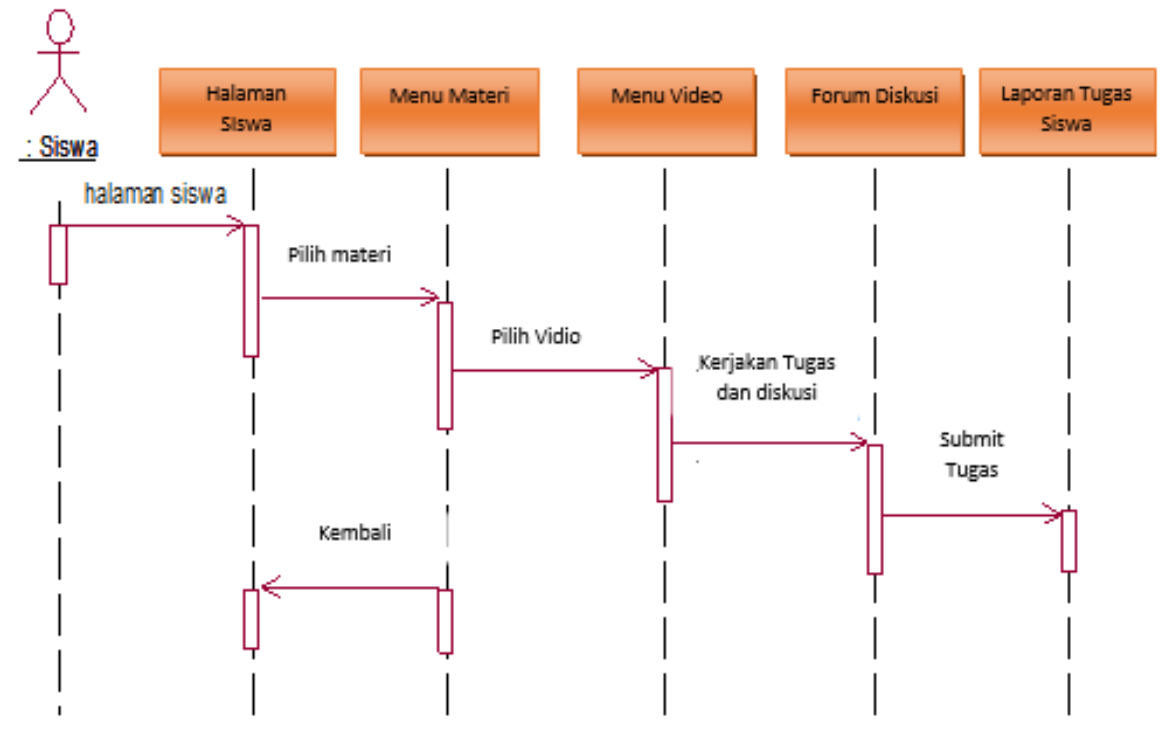

Gambar 6. Sequence Diagram Halaman Siswa

Gambar 6 adalah sequence diagram halaman siswa pada media Computer Based Instruction-Flipped Classroom, yang menjelaskan tentang runtutan pekerjaan user yaitu siswa pada halaman login di Computer Based Instruction-Flipped Classroom, dimana siswa dapat mengakses menu-menu yang ada pada Computer Based Instruction-Flipped Classroom yang terkait dengan pembelajaran, yaitu menu materi, menu video, menu tugas dan forum diskusi. 


\section{Pembahasan}

Pada penelitian ini menjelaskan tentang analisis kebutuhan serta desain atau rancang bangun sebelum Computer Based Instruction-Flipped Classroom dikembangkan. Hal ini sebagai kajian awal sebelum Computer Based Instruction-Flipped Classroom dikembangkan, agar menjadi pedoman bagi para guru ketika merancang Computer Based Instruction-Flipped Classroom tersebut, karena guru membutuhkan paradigma bagaimana mereka secara efektif dapat mengintegrasikan Computer Based Instruction-Flipped Classroom di dalam kelas nantinya.

Pada analisis kebutuhan siswa didapatkan bahwa Usia siswa SMK berada pada rentang 15 tahun sampai 18 tahun dimana siswa SMK tengah memasuki tahapan perkembangan masa remaja. Pada rentang usia tersebut, siswa memiliki kecenderungan menyukai warna-warna kontras, musik-musik dengan ritme, harmoni bernuansa lembut, menyenangi gambar animasi yang menarik, sehingga mereka dapat mengadaptasinya informasi dengan pikiran mereka sendiri sehingga mereka dapat memecahkan masalah-masalah kompleks yang abstrak (Trianto, 2012; Syah, 2005).

Berdasarkan kurikulum yang dipakai dalam proses pembelajaran di SMK pada mata pelajaran Komputer dan Jaringan Dasar, diperoleh materi yang akan dikembangkan dalam Computer Based Instruction-Flipped Classroom yaitu cara kerja internet, cara web berfungsi, cara mengatur jaringan operasional dan bagaimana memprogram jaringan untuk menyampaikan beragam aplikasi (Zaus \& Krismadinata, 2018). Pada mata pelajaran Komputer dan Jaringan Dasar ini, capaian pembelajaran yang harus dicapai oleh siswa adalah siswa harus menguasa konsep dasar jaringan komputer modern, siswa harus mampu mengembangkan aplikasi jaringan menggunakan bahasa pemrograman, siswa memahami arsitektur umum jaringan komputer dan bagaimana berlapis protokol jaringan komputer bekerja, siswa mampu mengidentifikasi dan menjelaskan topik saat ini di jaringan komputer, seperti keamanan dan kualitas layanan (Zaus \& Krismadinata, 2018).

Computer Based Instruction-Flipped Classroom ini didesain dengan menggunakan flowchart dan Unified Modelling Language (UML), dimana desain menggunakan UML tersebut terdiri dari usecase diagram dan sequence diagram. Hal ini sebagai kajian awal sebelum Computer Based Instruction-Flipped Classroom dikembangkan Berdasarkan analisis terhadap siswa, kurikulum, materi dan capaian pembelajaran tersebut, dijadikan pertimbangan dalam pengembangan Computer Based Instruction-Flipped Classroom agar Computer Based Instruction-Flipped Classroom yang akan dikembangkan nantinya bisa sesuai dengan kondisi pembelajaran dan karakteristik siswa. Serta berdasarkan desain Computer Based Instruction-Flipped Classroom menggunakan flowchart dan UML diharapkan Computer Based Instruction-Flipped Classroom dapat dikembangkan dengan efektif nantinya.

\section{SIMPULAN}

Berdasarkan tujuan dari penelitian ini yaitu untuk menentukan analisis kebutuhan dan desain dari Computer Based Instruction-Flipped Classroom dan hasil penelitian yang telah dilakukan, maka penelitian ini dapat disimpulkan bahwa 1) Usia siswa SMK berada pada rentang 15 tahun sampai 18 tahun dimana siswa SMK tengah memasuki tahapan perkembangan masa remaja. Karakteristik siswa pada usia tersebut memiliki kecenderungan menyukai warna-warna kontras, tetapi tidak mencolok. Memadukan komponen warna, musik, dan kreativitas siswa dalam belajar dengan menyenangkan dapat menumbuhkan 
motivasi siswa dalam belajar, maka dibutuhkan media yang menarik seperti Computer Based Instruction-Flipped Classroom; 2) Desain Computer Based Instruction-Flipped Classroom ini menggunakan flowchart, Unified Modeling Language (UML), yang terdiri dari desain use case, sequence diagram dan database yang digunakan pada Computer Based InstructionFlipped Classroom.

\section{REFERENSI}

Ahmed, S., \& Parsons, D. (2013). Abductive science inquiry using mobile devices in the classroom. Computers and Education, 63, 62-72. https://doi.org/10.1016/j.compedu.2012.11.017

Ai, H. (2017). Providing graduated corrective feedback in an intelligent computer-assisted language learning environment. ReCALL, 29(3), 313-334. https://doi.org/10.1017/S095834401700012X

Al Fatta, H. (2007). Analisis dan Perancangan Sistem Informasi. Yogyakarta: Andi Offset.

Amaral, L. A., \& Meurers, D. (2011). On using intelligent computer-assisted language learning in real-life foreign language teaching and learning. ReCALL, 23(1), 4-24. https://doi.org/10.1017/S0958344010000261

Bergmann, J., \& Sams, A. (2012). Flip your classroom: Reach every student in every class every day. International Society for Technology in Education, 1(2012).

Bernard, J. S. (2015). The Flipped Classroom: Fertile Ground for Nursing Education Research. Int. J. Nurs. Educ. Scholarsh., 12(1), 1-11. https://doi.org/10.1515/ijnes2015-0005

Berrett, D. (2012). How 'flipping' the classroom can improve the traditional lecture. The Chronicle of Higher Education, 58(21), 16-18.

Bull, G., Ferster, B., \& Kjellstrom, W. (2012). Inventing the Flipped Classroom. Learning \& Leading with Technology, 40(1).

Collins, A., \& Halverson, R. (2009). Rethinking Education in the Age of Technology. New York: Teachers College Press.

Crompton, H., Burke, D., Gregory, K. H., \& Gra, C. (2016). The Use of Mobile Learning in Science : A Systematic Review. https://doi.org/10.1007/s10956-015-9597-x

Evseeva, A., \& Solozhenko, A. (2015). Use of Flipped Classroom Technology in Language Learning. Procedia - Social and Behavioral Sciences, 206(November), 205-209. https://doi.org/10.1016/j.sbspro.2015.10.006

Hawkins, R. O. (2016). Using Computer-Assisted Instruction to Build Math Fact Fluency: An Implementation Guide. Intervention In School and Clinic, 1-7.

Hermann, M., Pentek, T., \& Otto, B. (2016). Design principles for industrie 4.0 scenarios. Proceedings of the Annual Hawaii International Conference on System Sciences, 2016March, 3928-3937. https://doi.org/10.1109/HICSS.2016.488

Jaschke, S. (2015). Mobile learning applications for technical vocational and engineering education: The use of competence snippets in laboratory courses and industry 4.0. Proceedings of 2014 International Conference on Interactive Collaborative Learning, ICL 2014, (December), 605-608. https://doi.org/10.1109/ICL.2014.7017840

Jia, J., Chen, Y., Ding, Z., Bai, Y., Yang, B., Li, M., \& Qi, J. (2013). Effects of an intelligent web-based English instruction system on students' academic performance. Journal of Computer Assisted Learning, 29(6), 556-568. https://doi.org/10.1111/jcal.12016

Kenna, D. C. (2014). A Study Of The Effect The Flipped Classroom Model On Student SelfEfficacy. North Dakota State University: Fargo, North Dakota.

Kleintein, U., \& Wannasawade, W. (2016). Development of blended learning model with virtual science laboratory for secondary students. Journal of Social and Behavioral 
Sciences, 217(2016), 706-711.

Marlowe, C. A. (2012). The effect of the flipped classroom on student achievement and stress. Montana State University, Bozeman, MT.

Mclaughlin, J. E., Roth, M. T., Glatt, D. M., Gharkholonarehe, N., Davidson, C. A., Griffin, L. M., ... Mumper, R. J. (2014). The Flipped Classroom : A Course Redesign to Foster Learning and Engagement in a Health Professions School, 89(2), 236-243. https://doi.org/10.1097/ACM.0000000000000086

Nolan, M. A., \& Washington, S. S. (2013). Flipped out: Successful strategies for improving student engagement. In Virginia Tech's Conference on Higher Education Pedagogy. Blacksburg, VA.

Overmyer, G. R. (2014). The Flipped Classroom Model For College Algebra: Effects On Student Achievement. Colorado State University: Fort Collins, Colorado.

Perez, R. G. (2016). Virtual Empathy as Digital Competence in Education 3.0. International Journal of Educational Technology in Higher Education, 13(20), 1-10.

Purnama, B. E., Setiawan, T. A., \& Riasti, B. K. (2017). Pembuatan Media Pembelajaran Interaktif Pengenalan Komputer Untuk Program Keahlian Teknisi Komputer. Indonesian Jurnal on Computer Science -, 9(3), 1-6.

Rahayu, L. P. (2017). Efektivitas Strategi Pembelajaran Flipped Classroom Pada Materi Pythagoras SMP Kelas VIII Ditinjau Berdasarkan Gender. Prosiding SI MaNIs (Seminar Nasional Integrasi Matematika Dan Nilai Islami), 1(1), 172-177.

Rosen, Y. (2009). The effects of an animation-based on-line learning environment on transfer of knowledge and on motivation for science and technology learning Yigal Rosen Faculty of Education University of Haifa Abstract. Journal of Educational Computing Research, 40(4), 451-467.

Sukardi, S., Puyada, D., Wulansari, R. E., \& Yanto, D. T. P. (2017). The validity of interactive instructional media on electrical circuits at vocational high school and technology. In the 2nd INCOTEPD (pp. 21-22). Yogyakarta: Universitas Negeri Yogyakarta.

Syah, M. (2005). Psikologi Pendidikan dengan Pendekatan Baru. Bandung: PT. Remaja Rosdakarya.

Trianto. (2012). Model Pembelajaran Terpadu: Konsep, Strategi dan Implementasinya Dalam KTSP. Jakarta: Bumi Aksara.

Wulansari, R. E., Puyada, D., Wijaya, I., \& Rukun, K. (2017). Effectiveness Of Instructional Media Based Game On Mathematics At Vocational High School. International Journal of Research Science and Management, 4(12), 125-128. https://doi.org/10.5281/zenodo.1134077

Zaus, M. A., \& Krismadinata. (2018). Suatu Kajian Literatur Masalah- Masalah yang Dihadapi dalam Mata Kuliah Jaringan Komputer. Journal Inovasi Vokasional Dan Teknologi, 18(1), 1-8. 